\title{
MIGUEL DE QUINTANA, AUTOR DE LA PORTADA DEL CONVENTO DE LA MERCED, ACTUAL MUSEO DE BELLAS ARTES DE SEVILLA
}

\author{
por ANA MENDIOROZ LACAMBRA
}

El convento de la Merced, actual Museo de Bellas Artes de Sevilla, fue realizado en los años finales del siglo XVI por Juan de Oviedo y es uno de los edificios señeros de la arquitectura hispalense. Según su planta, aún visible en el plano de Olavide, ocupaba este edificio toda la manzana comprendida entre las actuales calles Alfonso XIII y Bailén, de norte a sur, y Cepeda y M. de Carvajal, de este a oeste.

Antonio Sancho Corbacho, González de León, Pérez Escolano y Suárez Garmendia son algunos de los historiadores de arte que de forma más directa se han ocupado de este edificio. Quizás las aportaciones del primero sean las más innovadoras, al desentrañar toda una serie de remodelaciones perfectamente documentadas que experimenta su recinto durante el s. XVIII.

En cualquier caso, la pieza más controvertida del antiguo convento de la Merced, en lo que a autoría se refiere, es la portada que hoy da acceso al dicho Museo y aunque fue concebida como entrada principal para la antigua iglesia de esta Casa Grande, ubicándose durante años a los pies de la misma, es en los años cuarenta cuando se tralada a su lugar actual, debido a una serie de remodelaciones efectuadas en el edificio con el fin de convertirlo en Museo de Bellas Artes.

Se ha venido atribuyendo la portada al círculo del arquitecto sevillano dieciochesco Lorenzo Fernández de Iglesias por aproximación coetánea y estilística con algunas de sus obras ya documentadas. Afortunadamente, en el Archivo de Protocolos Notariales de Sevilla, hemos encontrado el contrato de obra que permite su restitución a un maestro cantero sevillano, coetáneo y estrechamente vinculado a Lorenzo Fernández de Iglesias. Se trata de Miguel de Quintana. 
Según las condiciones estipuladas en este contrato se haría de mármol y piedra martelilla, todo ello según el diseño firmado por el Reverendo Padre Francisco Bartolomé de Roxas, comendador de dicho convento, y del ya mencionado Miguel de Quintana.

Constituyen el alzado de esta portada, dos cuerpos perfectamente definidos, y ordenados a base de columnas, que como muy bien indica el contrato de obra, han de ser de orden compuesto «que es lo que corresponde a buena arquitectura». En el piso superior, y centrada por una hornacina, había de ubicarse la «imagen de Ntra. Sra. (de la Merced) y dos captivos a los lados», de acuerdo con la conocida composición iconográfica de la Virgen de la Misericordia.

La fecha del contrato para realizar esta obra, es de diez de Marzo de 1729, obligándose a finalizarla para el último día de Febrero del año siguiente. El precio tasado por el maestro cantero, es de diez y seis mil reales de vellón.

\section{APENDICE DOCUMENTAL}

Contrato de la portada del convento de la Merced de Sevilla. Archivo de Protocolos Notariales de Sevilla, Oficio 17, Libro $1 .^{\circ}$ de 1729 , fols. 60 r.-62 v.

«Sepase como nos, Miguel de Quintana, arquitecto y maestro de canttero vezino destta ciudad de Sevilla al sitio del Postigo del Azeyte, como principal obligado; y Thomas Alonso Romero y F. Bermudez, oficiales del dicho ofizio y vezinos de ella en dicho sittio y Juan Chirino, ofizial del mismo ofizio, vezino de estta dicha ciudad juntto a la Puerta de Triana, como fiadores y principales pagadores y obligados que del dicho pricipal nos consttittuimos y salimos en lo que por estta scriptura sera declarado. Hacemos de negosio ajeno nuestro propio sin que contra el suso dicho ni sus bienes ni contra otra persona alguna preseda ni se aga diligensia ni excursión (fórmulas) Ottorgamos en favor del Real Combento de Nuestra Señora de la Merced Redempzion de Captivos Cassa Grande destta dicha ciudad que Comendador y deposittarios que son y fueren del en adelante y desimos por quanto yo, el dicho prinzipal esttoy convenido y conserttado condicho combento en hazer en el una porttada en la forma con las condisiones, obligaziones, presio y demas zircunstanzias que se an declarado y cuio combenio quiero redusirlo a escripttura publica que estta presente, y por ella todos quatro prinsipal y fiadores como siertos sabedores y bien informados de nuestro derecho y obligazion que en estte caso nos combiene hazer otorgamos; que nos obligamos bajo de la dicha mancomunidad y fianza fecha, que tenemos de hazer una portada para la puerta prinzipal de la iglesia de dicho combento de Nuestra Señora de la merced que 
a el presente afronta con el Altar mayor de ella, la qual a de ser de marmol y piedra marttelilla y los pedestales asi sus bazamenttos y capitteles an de ser del mismo marmol como los lados de dicha imagen de Ntra. señora y dos captivos a los lados de dicha imagen, que emos de poner en dicha porttada con la grandesa y simetria que el nicho permittiere y lo demás del resto de dicha piedra marttella de buena calidad y sin defectto que para ello tenga. Componiendose el primer cuerpo de diez baras menos media quarta de altta segun su pie, como demuestra un dizeño modelo que se a demostrado y estta sombreado y firmado del reverendo padre Francisco Bartolomé de Roxas, comendador de dicho combento y de mi el dicho pinzipal y que estta solo sirbe para en quanto el primer cuerpo por esttar en buena proporzion de arquitectura no ussandose del segundo cuerpo de dicho diseño o modelo, por esttar desproporsionado según buena simetría y proporssion. En cuio primer cuerpo, en los intercolumnios, esttan unas repisas y conchas resartadas, las quales no emos de hazer por ser el sitio estrecho y no poder guardar buena proporsion, y en lugar de las columnas salomonicas que el dicho cuerpo demuestra se an de colocar las que manifiesta un papel y perfil que estta firmado de dicho padre comendador y de mi, el dicho prinsipal, cuio perfil es de orden compuesto y los sobre puestos de talla que dicho columnas tienen, an de ser del mas bajo relieve que pudiere permitir según su tamaño. $Y$ el segundo cuerpo que se a de colocar ensima del primero que queda referido, a de ser segun el que demuestra dicho diseño que se a demostrado, también estta firmado de dicho padre comendador y de mi, el dicho prinsipal. Si de suerte que colocado este segundo cuerpo ensima del primero queda referido haya de tener de altto como tiene de ancho astta debajo del fronttis. En estta forma estta el dicho cupero entero demostrado, y en ella nos obligamos todos, prinsipal y fiadores de labrarlo por sima de dicho primer cuerpo, guardando la proporsion espresada en el ancho que alli corresponde; las motivos que esttan en las pilastras del dicho segundo cuerpo, an de ser Capiteles de orden compuesto, que es lo que perteneze a buena arquitectura, y según ella an de ser los perfiles y buelos que en dicha fábrica se an de executar. Y en quanto a los masisos y enttravados de piedras, son de pedestales como del todo el seguro que a de llevar para su perpettuidad a de ser quales dichos pedestales por la parte de su mocheta y los paños de la puerta sean de una piesa hasta que coxiendo todo el pedestal se lleguen al pasar por la entrecalle las unas sobre las otras en la conformidad de la mexor trabazon, sin que siempre se an de dejar de attender a que la mocheta de la puerta que es el pilastron que rezive el arco, aya de ir agregado a el referido pedesttal de la primera columna, pues de otra manera sería la dicha obra dessunida y sin la seguridad nesesaria la qual enttrar astta coxer parte del relame; en el ottro pilastron de la columna de fuera a de tener entrada a lo menos de media bara para que la obra que sobre sobre los dichos pedesttales, tenga donde azer firme y seguro sus gradas y sea fundamento de lo elevada que sobre el a de levantar. En estta misma conformi- 
dad seguiran las mismas piesas asta el arranque o imposta, la qual a de ser segun artte y que aora no demuestra el dicho diseño y a de tener un modulo de grueso con sus fajas y perfiles de la dicha horden compuesta. Y desde la dicha imposta hasta la cornisa se an de entregar, y a ello nos obligamos, en la pared fuera de los buelos, las iladas unas media bara, y ottras un pie y las cornizas tendran de entrada, tanto como tienen de buelo o algo más y ara que sirba de sujesion a dicho primer cuerpo y de fundamento a el, según lo que cargaran sus pedestales sobre los masisos de las columnas del primero. Y el segundo a de guardar la misma forma, entrando unas iladas media bara, y otras una tersia asta la cornisa; y tendra de entrada lo mismo que bolar. las figuras o angeles an de ser de la misma esttattura que demuestra el dicho dizeño y su excudo a de ser de proporsión y buena simetría, y las entradas que se rompieron en los muros o pared de dicha iglesia para entrago de las piedras, se an de masisar con buen muro, con la seguridad de dicha pared y porttada hasiendo un cuerpo solido y masiso con la condizion que desde el prinzipio de dicha obra y en que se abrier el simiento y pusiese el banquillo de dicha portada, se a de poder por parte del dicho combento, nombrar un maestro de la satisfazion para que rexistre la seguridad de dicho simiento, entrada de piedra de dicha portada y los de aquellos que se casaren en dicha pared, y de su pareser por el qual nos obligamos de esttar y faser y no por el de otro maestro alguno para en quanto a la dicha obra y no mas como todas las demas vezes que paresiere a dicho combento y si por el pareser que sobre ello diere el referido maestro constare no ir dicha obra con la seguridad que se requiere, abemos de volber a zer de nuebo hastta y perfecttamente quedare a satisfazion y seguridad sin malestar que asi se nombrare, porque debajo de estta condizion a tenido efecto dicha obra. Y de ottra suerte no lo tubiera la que nos obligamos de dar fenesida y acavada en toda premura sin faltar en cossa alguna de lo que va referido para el dia fin del mes de febrero que bendra de este presente año de la fecha. Costeándolo a nuestra costa, assi jornales, materiales, tablasones, andamios y todo lo demás que sea necesario asta la conclusion de dicha porttada, sin que el dicho combento tenga obligazion a darnos cosa alguna mas que tan solamente la canttidad que adelante sera declarada (fórmulas) La qual dicha porttada nos obligamos de azer en dicha forma y en presio de dies y seis mil reales de vellón en que la teniamos ajustada, los que se nos an de pagar y satisfazer en esta forma: siette mil y ochosientos y zinquenta reales que a mi el dicho pinzipal se me an de entregar a quenta de ellos por ser y parar en mi poder, me doi por entregado a mi boluntad (fórmulas). Otorgo cartta de pago en forma de los dichos fiadores y aprovamos y ratificamos en mil y siento y zinquenta reales cumplimiento ante nuebe mill que se nos an de entregar luego que conste esttar el banquillo o pedestal de marmol de dicha portada, que llega asta el arranque del astro lunar del dicho primero cuerpo. Dos mill reales que se nos an de entregar, luego que este puesto el friso que estta debajo de la cornisa Otros dos mill en lle- 
gando al escudo o remate de la dicha portada, llegado que esttara dicha obra astta la imposta o arranque del arco que cubre la imagen; y los mil reales restantes, se nos an de dar y presentar, luego que conste y se justifique estar dicha obra fenesida y acabada, esto, a la progresion y satisfazion de tal maestro que asi fuere nombrado, $o$ a la de las demas pesonas que de ello entienden bien y cumplidamente (fórmulas). El comendador y relixiosas a saver el maestro Fco. Bartlomé de Roxas, comendador=el Padre Fco. Perez Solana=y Fco. Marttin Ramirez, depositarios y todos por razon de nuestros ofizios de administradores y abiendo oydo estta escriptura, otorgamos que la aseptamos en todo y por todo segun y como en ella se contiene y obligamos al dicho combento con sus vienes y sus rentas a la paga de los diez y seis mil reales de vellon a los plasos y en las formas que en estta escriptura se declara(fórmulas). Fecha la carta en Sevilla en diez dias del mes de Marzo de Mil y settesientos y veinte y nuebe años...». 


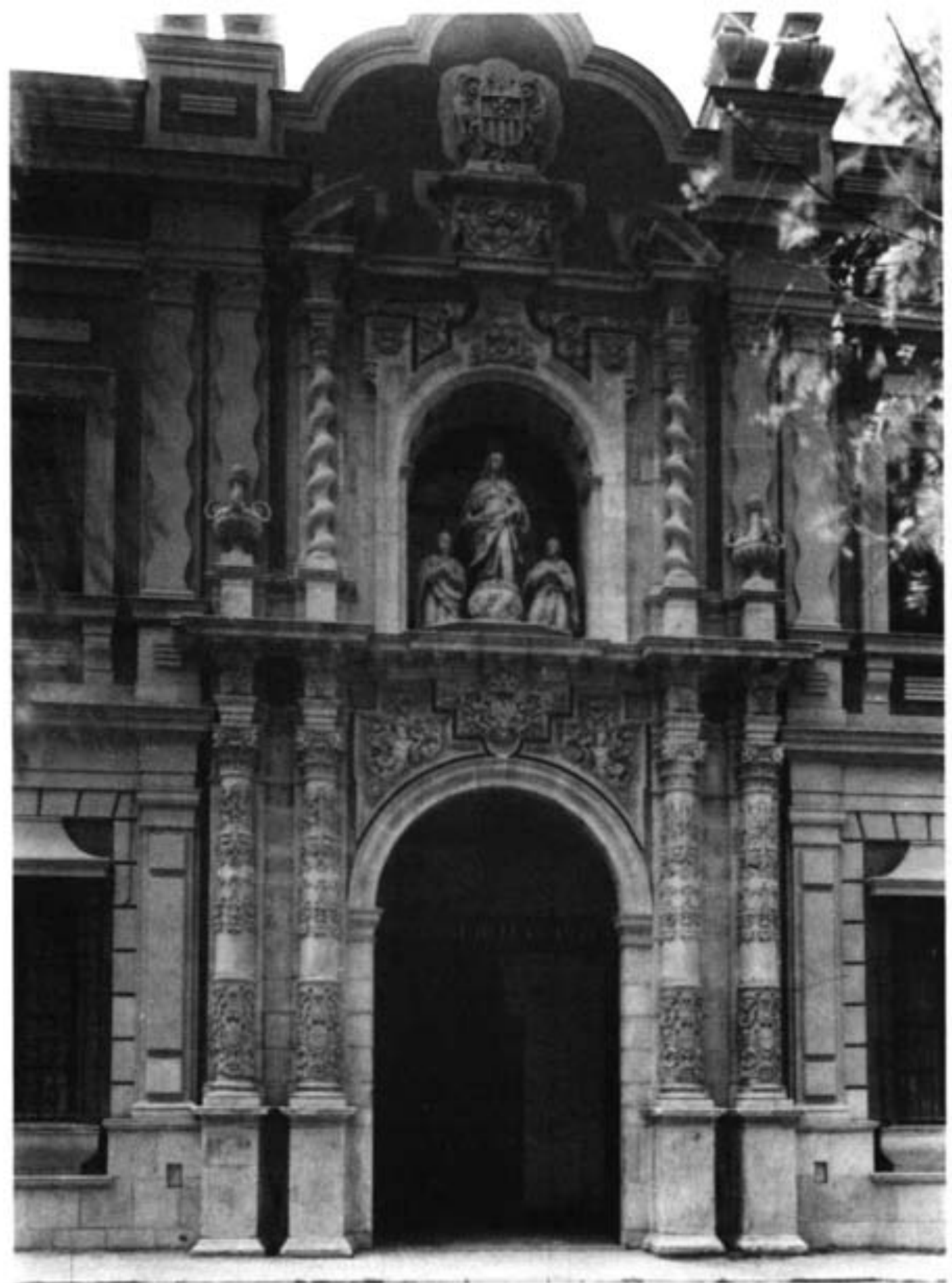

Miguel de Quintana (1729). Portada principal de la iglesia del Convento de la Merced (actual Museo de Bellas Artes). Sevilla. 